\title{
Overexpression of Brain-Derived Neurotrophic Factor Protects Large Retinal Ganglion Cells After Optic Nerve Crush in Mice
}

\author{
(ㄴ)Liang Feng, ${ }^{1,2}$ (D) Zhen Puyang, ${ }^{1,3,4}$ Hui Chen, ${ }^{1,2}$ Peiji Liang, ${ }^{4}$ John B. Troy, ${ }^{3}$ and ${ }^{\circledR}$ Xiaorong Liu ${ }^{1,2}$ \\ DOI:http://dx.doi.org/10.1523/ENEURO.0331-16.2016 \\ ${ }^{1}$ Department of Ophthalmology, Feinberg School of Medicine, Northwestern University, Chicago, IL 60611, USA, ${ }^{2}$ Department of \\ Neurobiology, Weinberg College of Arts and Sciences, Northwestern University, Evanston, IL 60208, USA, ${ }^{3}$ Department of Biomedical \\ Engineering, Robert R. McCormick School of Engineering and Applied Science, Northwestern University, Evanston, IL 60208, USA, \\ and ${ }^{4}$ School of Biomedical Engineering, Shanghai Jiao Tong University, Shanghai 200240, China
}

\begin{abstract}
Brain-derived neurotrophic factor (BDNF), a neurotrophin essential for neuron survival and function, plays an important role in neuroprotection during neurodegenerative diseases. In this study, we examined whether a modest increase of retinal BDNF promotes retinal ganglion cell (RGC) survival after acute injury of the optic nerve in mice. We adopted an inducible Cre-recombinase transgenic system to up-regulate BDNF in the mouse retina and then examined RGC survival after optic nerve crush by in vivo imaging. We focused on one subtype of RGC with large soma expressing yellow fluorescent protein transgene that accounts for $\sim 11 \%$ of the total SMI-32positive RGCs. The median survival time of this subgroup of SMI-32 cells was 1 week after nerve injury in control mice but 2 weeks when BDNF was up-regulated. Interestingly, we found that the survival time for RGCs taken as a whole was 2 weeks, suggesting that these large-soma RGCs are especially vulnerable to optic nerve crush injury. We also studied changes in axon number using confocal imaging, confirming first the progressive loss reported previously for wild-type mice and demonstrating that BDNF up-regulation extended axon survival. Together, our results demonstrate that the time course of RGC loss induced by optic nerve injury is type specific and that overexpression of BDNF prolongs the survival of one subgroup of SMI-32-positive RGCs.
\end{abstract}

Key words: brain-derived neurotrophic factor (BDNF); in vivo imaging; neuroprotection; optic nerve crush; retinal ganglion cells (RGCs)

\section{Significance Statement}

The primary goal of this study was to investigate the role of BDNF on RGC survival after optic nerve injury. We adopted an inducible Cre-recombinase transgenic system to modestly up-regulate BDNF in the mouse retina. We then applied a live imaging technique to track the survival of RGCs expressing yellow fluorescent protein in vivo. We identified one type of RGC with a large soma that accounts for $\sim 11 \%$ of the total SMI-32-positive RGCs. Our results showed that these SMI-32-positive large-soma cells were susceptible to acute optic nerve injury. Furthermore, we found that BDNF up-regulation promoted survival of these large-soma SMI-32-positive RGCs. Our study thus adds new insights on better understanding of type-specific RGC loss after optic nerve injury and the underlying BDNF-mediated neuroprotective mechanism.

\section{Introduction}

Optic neuropathy refers to optic nerve injury resulting in optic atrophy and retinal ganglion cell (RGC) dysfunction,

Received November 3, 2016; accepted December 28, 2016; First published January 05, 2017.

The authors declare no competing financial interests. induced by insults such as glaucoma or acute damage to the optic nerve. Different animal models of experimental optic neuropathy have been created to examine RGC performed the experiments and data analysis; L.F., Z.P., and X.L. prepared 
degeneration and its underlying mechanisms (Morrison et al., 2011; Calkins, 2012; Puyang et al., 2015). Recent studies, including ours, suggest that RGCs degenerate in a type-specific order (Della Santina et al., 2013; Feng et al., 2013; Chen et al., 2015; Duan et al., 2015; El-Danaf and Huberman, 2015; Ou et al., 2016). One study reported that OFF arbors of all RGC subtypes were damaged by a transient elevation of intraocular pressure (IOP; El-Danaf and Huberman, 2015), whereas we have found that both OFF RGCs and ON RGCs are impaired in mice with mild and sustained IOP elevation (Feng et al., 2013, 2016; Chen et al., 2015). Della Santina et al. (2013) reported that OFF transient RGCs are particularly vulnerable to IOP elevation, yet another study reported that SMI-32-labeled RGCs, which also include some OFF transient RGCs, are resistant to optic nerve crush injury (Duan et al., 2015). The absence of an agreed basis on which to classify mammalian RGCs (Sanes and Masland, 2015) and potential variation in RGC susceptibility to different optic neuropathies may account for some interstudy inconsistency. It is now claimed that there are $>30$ types of murine RGCs (Baden et al., 2016); thus classifications based solely on center response polarity (OFF, ON, ON-OFF) or response dynamics (sustained, transient) provide insufficient permutations to account for so many RGC subtypes. Thus, if susceptibility of different RGC subtypes to optic neuropathy is to be characterized well, other means of cell identification are needed.

Brain-derived neurotrophic factor (BDNF) plays important roles in neural development, survival, and function (Huang and Reichardt, 2003), as well as in neuroprotection during neurodegenerative disorders (Nagahara and Tuszynski, 2011). A series of studies has suggested that BDNF protects RGCs in experimental glaucoma (Johnson et al., 2009, 2011; Danesh-Meyer, 2011; Chader, 2012). Different approaches have been used to manipulate BDNF levels, such as intravitreal injection of BNDF protein, infection with adeno-associated virus expressing BDNF for gene therapy, and transplantation of stem cells in animal models of experimental glaucoma or optic neuropathy (Mey and Thanos, 1993; Chen and Weber, 2001;

the Figures; L.F., Z.P., and X.L. wrote the manuscript, L.F., Z.P., H.C., P.L., J.B.T., and X.L. edited and approved the manuscript.

This work was supported by the National Institutes of Health (NIH) grant R01EY026286 (X.L.) and grants from the BrightFocus Foundation (L.F. and X.L.), Northwestern Memorial Foundation (X.L.), Research to Prevent Blindness (Department of Ophthalmology), National Natural Science Foundation of China (P.L., NSFC No. 31471054), and the Program of Introducing Talents of Discipline to Universities (P.L., No. B08020).

L.F. and Z.P. contributed equally to this work.

Acknowledgments: We thank Ting Lv and Mingna Liu for helping with axon counting and data analysis, and the Biological Imaging Facilities (BIF) at Northwestern University for confocal microscopy.

Correspondence should be addressed to Xiaorong Liu, Hogan 2-160, 2205 Tech Drive, Northwestern University, Evanston, IL 60208. E-mail: xiaorongliu@northwestern.edu.

DOI:http://dx.doi.org/10.1523/ENEURO.0331-16.2016

Copyright (C) 2017 Feng et al.

This is an open-access article distributed under the terms of the Creative Commons Attribution 4.0 International, which permits unrestricted use, distribution and reproduction in any medium provided that the original work is properly attributed.
Martin et al., 2003; Harper et al., 2011). However, incomplete protection or insufficient rescue by BDNF were often observed in different models (Di Polo et al., 1998; Ko et al., 2001; Pease et al., 2009), and the mechanism underlying BDNF-mediated neuroprotection is not known.

We found recently that a modest increase of retinal BDNF protects some RGC subtypes in a mouse model of experimental glaucoma (Feng et al., 2016). Here we have investigated how BDNF affects RGC subtype survival in an acute model of optic nerve injury. As in our earlier study, we used a tamoxifen-induced Cre-ER system to up-regulate BDNF in the mouse retina (Feng et al., 2016). $A$ rapid loss of $R G C$ s was induced by crush of the optic nerve, and the effect of BDNF upregulation on RGC survival assessed by using a previously established in vivo imaging approach (Puyang et al., 2016).

\section{Materials and Methods}

\section{Animals}

BDNF-overexpression (BDNF_OE) mice were generated as described previously (Feng et al., 2016): BDNF ${ }^{\text {stop }}$ mice, which carry a stop cassette flanked by loxP inserted before the BDNF coding region, were crossed with Thy1-CreER ${ }^{\mathrm{T} 2}$ transgenic mice that carry both enhanced YFP and CreER recombinase driven by the Thy-1 promoter (The Jackson Laboratory, stock no. 007606). One intraperitoneal injection of tamoxifen $(10 \mathrm{mg} / \mathrm{kg}$, dissolved in sunflower seed oil) was administered to turn on transcription of the BDNF transgene in adult Thy-1-CreER ${ }^{\mathrm{T} 2}:$ :BD$\mathrm{NF}^{\text {stop }}$ mice of either sex, thus creating BDNF_OE mice (Feng et al., 2016). All animal procedures were approved by the Northwestern University Institutional Animal Care and Use Committee and performed in accordance with the guidelines on the Use of Animals in Neuroscience Research from the National Institutes of Health and the Society for Neuroscience.

\section{Optic nerve crush surgery}

The optic nerve crush (ONC) surgery was performed on left eyes only (Leung et al., 2011; Puyang et al., 2016). In brief, a small opening was created in the superior and lateral conjunctiva of the anesthetized mouse (Puyang et al., 2016). A pair of self-clamping forceps (\#7, WPI) was used to clamp the optic nerve $0.5-1 \mathrm{~mm}$ behind the globe for 3 s (Puyang et al., 2016). Body temperature was maintained using a heating pad (Sunbeam) until mice were fully awake.

\section{In vivo imaging}

In vivo images of retinas were captured via a Micron III fundus scope (Phoenix Research Laboratories; Puyang et al., 2016). Retinal images were taken before ONC (baseline) and at different time points after ONC. Images were then imported and processed by a customized Matlab program (The Mathworks). RGCs with soma diameter $>21 \mu \mathrm{m}$ were selected by the Matlab program, whose reliability was confirmed manually by two independent observers. We also compared the counting results from in vivo images with the soma counts from confocal images of the same retinas and found a strong positive correlation 
A

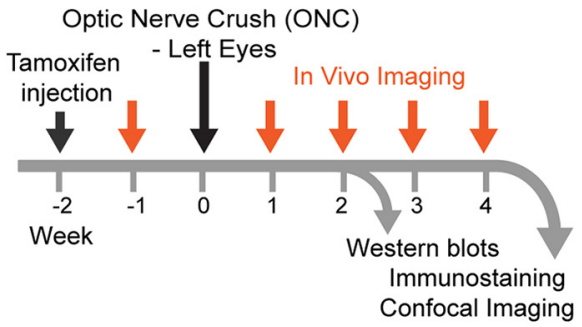

B

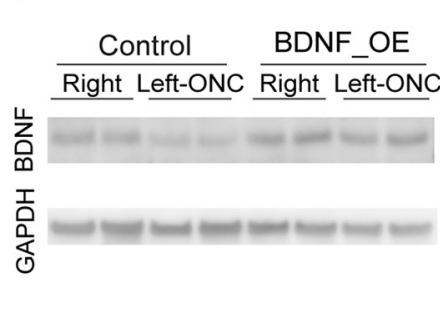

C

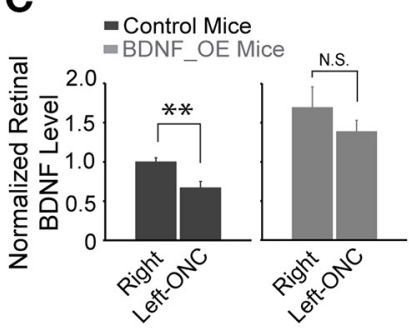

D In Vivo Imaging Identification of Large-soma RGCs
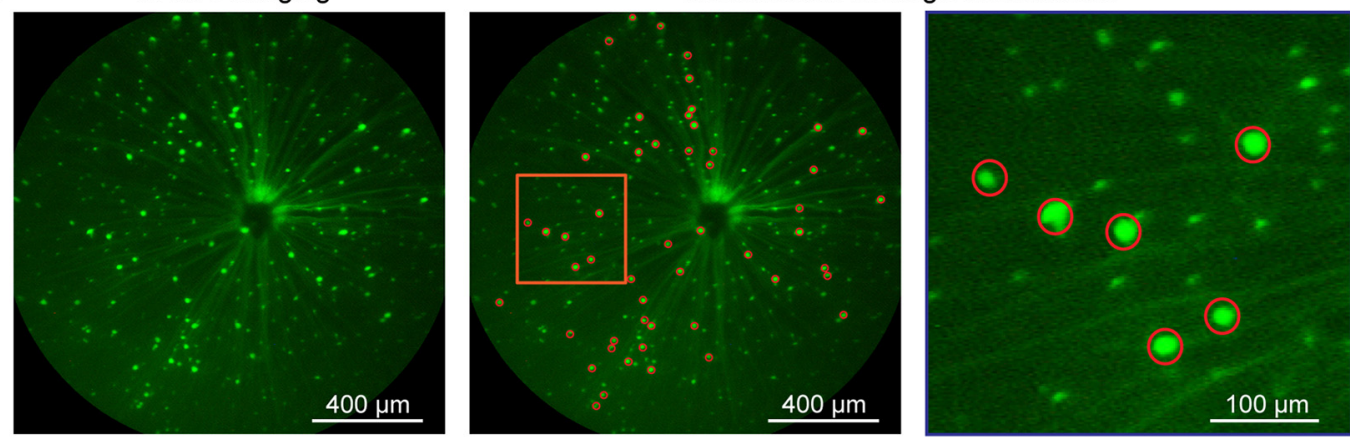

Figure 1. Experimental design to investigate the neuroprotective role of BDNF after ONC. $\boldsymbol{A}$, Timeline of experiments. $\boldsymbol{B}, \boldsymbol{C}$, Retinal BDNF levels were quantified by Western blot analysis. Left eyes received ONC, and relative protein levels were compared to the level of nonoperated right eyes (with right eyes of control mice designated as 1). BDNF_OE compensated for the down-regulation of retinal BDNF level induced by ONC. $n=4-7$ mice in each group. N.S.: not significant; $* * p<0.01$ by Student's $t$-test. $\boldsymbol{D}$, In vivo imaging to identify a small group of large-soma RGCs. Left, a representative Thy-1-CreER ${ }^{T 2}$ mouse retina imaged by a Micron III fundus scope. Middle, the image was processed by Matlab to identify large-soma RGCs (marked by red circles). The area marked by the orange square was highlighted on the right.

between the counts $\left(R^{2}=0.89\right.$; Puyang et al., 2016). The survival rate of RGCs for each retina was expressed as the ratio of surviving RGCs to the total RGC number before ONC (baseline). The Kaplan-Meier estimator was used to give the probability of RGC survival (Puyang et al., 2016). A log-rank test was performed to compare survival distributions of different groups (Puyang et al., 2016).

\section{Immunohistochemistry and Western blot analysis}

Whole-mounted retinas were prepared for immunostaining and retinal protein samples for Western blot analysis as described previously (Liu et al., 2007; Yoshida et al., 2011; Puyang et al., 2016; Feng et al., 2016). Primary antibodies for immunostaining included rabbit anti-green fluorescent protein (anti-GFP; 1:1000; Thermo Fisher Scientific, A-6455), mouse anti-Brn-3a (1:400; EMD Millipore, MAB1585), goat anti-Brn-3b (1:1000; Santa Cruz Biotechnology, sc-6026), mouse anti-TH (tyrosine hydroxylase, 1:400, EMD Millipore, MAB318), choline acetyltransferase (ChAT; 1:200; EMD Millipore, MAB305; Liu et al., 2007), BETA3 (also known as BhlhB5, 1:1000; Santa Cruz Biotechnology, sc-6045; Feng et al., 2006), cocaine- and amphetamine-regulated transcript (CART; 1:2500, Phoenix Pharmaceuticals), SMI-32 (neurofilament $\mathrm{H}$ non-phosphorylated, 1:1000, Covance; Feng et al., 2013), rabbit anti-BDNF (1:400; EMD Millipore, Ab1779SP; Feng et al., 2016), and mouse anti-GAPDH (1:2000, EMD Millipore, MAB374; Yoshida et al., 2011). Alexa Fluor-conjugated secondary antibodies were used (1:1000; Invitrogen), and images were captured with a
Zeiss Pascal confocal microscope. Western blot analysis was performed using rabbit anti-BDNF (1:400; EMD Millipore, Ab1779SP) and mouse anti-GAPDH (1:2000, EMD Millipore, MAB374; Feng et al., 2016).

\section{Axon counts}

Automatic axon counting was performed using a customized Matlab program as described previously (Puyang et al., 2016). Confocal images were taken of the flatmounted retinal samples immunostained with GFP antibody. After positioning the center of the optic nerve head $(\mathrm{ONH})$ in the image, the signal intensity at 200 and $400 \mu \mathrm{m}$ radially surrounding the $\mathrm{ONH}$ was recorded, locating axons based on the local maxima (Puyang et al., 2016). After the contrast and brightness of the images were adjusted in Photoshop (Adobe Systems), two independent observers confirmed the number of axons manually.

\section{Results}

\section{Effect of BDNF loss induced by ONC was compensated in BDNF_OE mice}

We induced an acute loss of RGCs by ONC and determined whether overexpression of BDNF aided RGC survival (see schematic experimental design in Fig. $1 A$ ). We generated conditional BDNF-OE mice using the tamoxifen-induced Cre-recombinase system as described previously (Feng et al., 2016). ONC surgery was performed in left eyes, and the retinal BDNF levels were compared with the nonoperated right eyes of the same mice (Fig. 1B, C). At 2 weeks after the ONC injury, the 
A

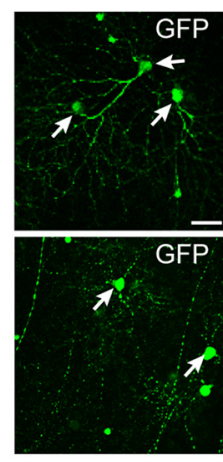

RGC markers

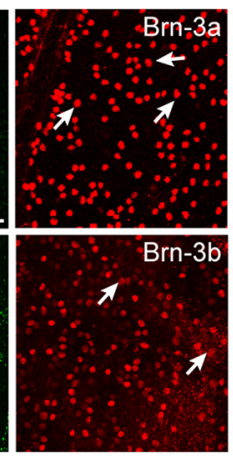

C
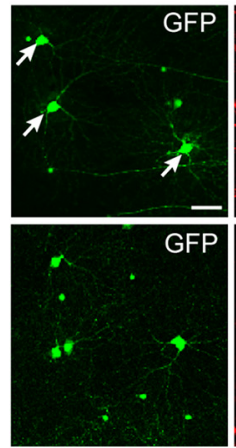

RGC subtype markers

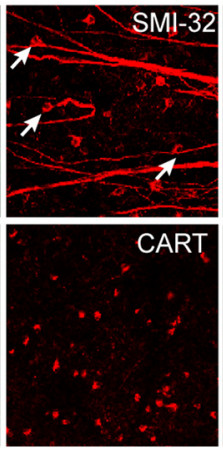

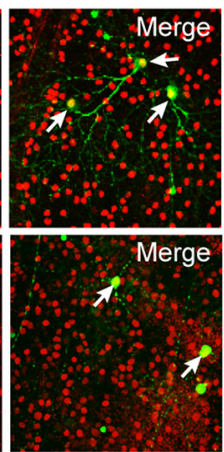

B

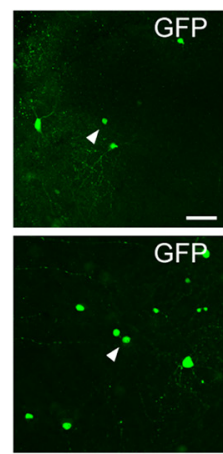

Amacrine cell markers

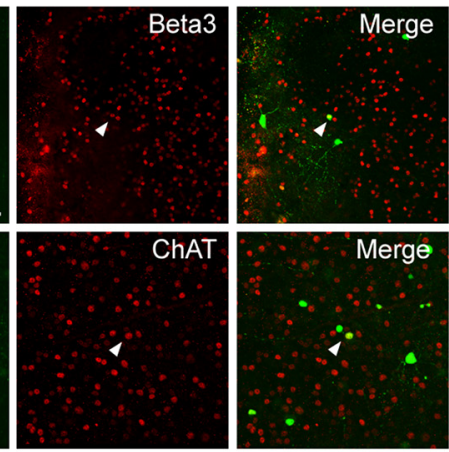

E

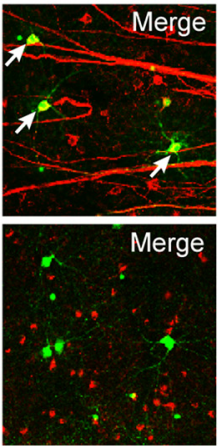

D

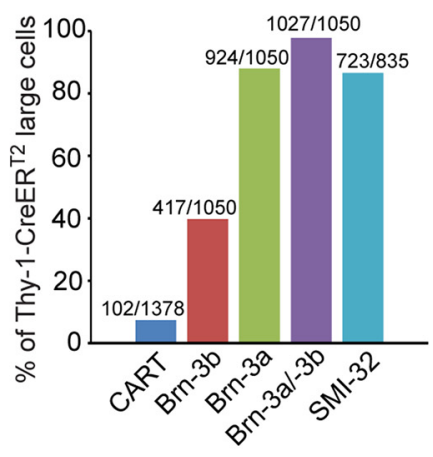

SMI-32 Thy-1-CreER ${ }^{T 2}$

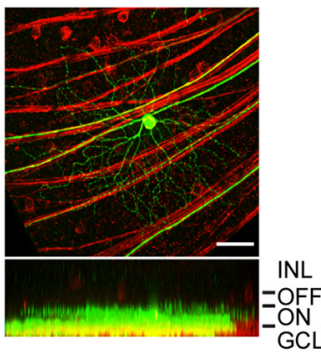

Figure 2. Identification of one type of RGCs with large somas. $\boldsymbol{A}$, GFP-positive cells with large somas expressing Thy-1-CreER ${ }^{\mathrm{T} 2}$ transgene were coimmunolabeled with RGC markers: Brn-3a and Brn-3b (arrows). B, Small-soma, but not large-soma, GFP-positive cells were coimmunolabeled with amacrine cell markers: BETA3 and ChAT (arrowheads). C, GFP-positive cells with large somas were coimmunolabeled with RGC subtype markers: SMI-32 (arrows), but not with CART. $\boldsymbol{D}$, Percentages of large-soma RGCs expressing Thy-1-CreER ${ }^{\text {T2 }}$ transgene coimmunolabeled with different RGC markers. $\boldsymbol{E}$, Confocal image of one large-soma RGC double-labeled by SMI-32 (red) and GFP (green). Orthogonal view of the same cell is shown at the bottom. Most SMI-32 and GFP cohorts in large RGCs (20 of 28) had their dendrites laminated in ON sublamina of IPL. Scale bars: $50 \mu \mathrm{m}$. INL, inner nuclear layer.

BDNF level of left eyes from control mice was downregulated $33 \%(0.67 \pm 0.08)$ compared with the nonoperated right eyes (normalized as $1, p<0.01$ by Student's t-test; Fig. $1 B, C)$. In contrast, in BDNF_OE mice, the down-regulation of BDNF of left eyes induced by ONC injury was compensated for by BDNF overexpression (left, $1.70 \pm 0.26$ vs. right, $1.39 \pm 0.15 ; p=0.33$ by Student's t-test; Fig. 1B, C).

In this study, we used the Micron III fundus scope to track RGC loss after ONC injury (Feng et al., 2016). In the Thy-1-CreER ${ }^{\mathrm{T} 2}$ ::BDNF ${ }^{\text {stop }}$ mice, YFP-labeled somas of varying size were scattered across the retina within the ganglion cell layer (GCL; Fig. 1D, left). Because both RGCs and displaced amacrine cells are found in the GCL, we chose to focus on the effect of BDNF protection after ONC on one RGC subtype.

\section{Selection of large-soma RGCs}

Because amacrine cells generally have smaller somas than RGCs (Sun et al., 2002), we selected only cells with soma diameter $>21 \mu \mathrm{m}$ to exclude amacrine cells from this study (Fig. 1D, middle and right). To rule out the possibility that a number of amacrine cells may be included in the cell sample studied, we performed doubleimmunolabeling with amacrine cell marker ChAT, which labels starburst amacrine cells, and BETA3, which labels a small portion of displaced amacrine cells. We found that 0 of 343 ChAT-positive and of 179 BETA3-positive amacrine cells were colabeled with large-soma YFP-positive cells (Fig. 2B).

To confirm that the cells with large somas were RGCs, we used double-immunolabeling with the RGC markers Brn-3a and Brn-3b (Fig. 2A, D). We found that $98 \%$ of YFP-positive RGCs with large somas colabeled for Brn-3a (88\%) or Brn-3b (40\%; Fig. 2A, D). We further identified RGC subtypes using SMI-32, a marker for large alpha cells, and CART, a marker for ON-OFF direction-selective RGCs. Eighty-seven percent of large-soma RGCs colabeled for SMI-32, but only $7.4 \%$ for CART (Fig. 2C, D). In other words, most large-soma Thy-1-positive cells are SMI-32-positive RGCs. Moreover, these large-soma RGCs account for only $10.8 \%$ of the total SMI-32-positive cells (723 of $6723 \mathrm{SMI}-32^{+}$cells; $n=4$ retinas).

To further identify whether these SMI-32-positive cells were ON or OFF RGCs, we examined their dendritic lamination pattern by confocal imaging. We identified 28 large-soma cells that were SMI-32- and YFP-positive and found that 20 of 28 cells were ON type, with dendrites in the ON sublamina of inner plexiform layer (IPL; Fig. 2E). 
A
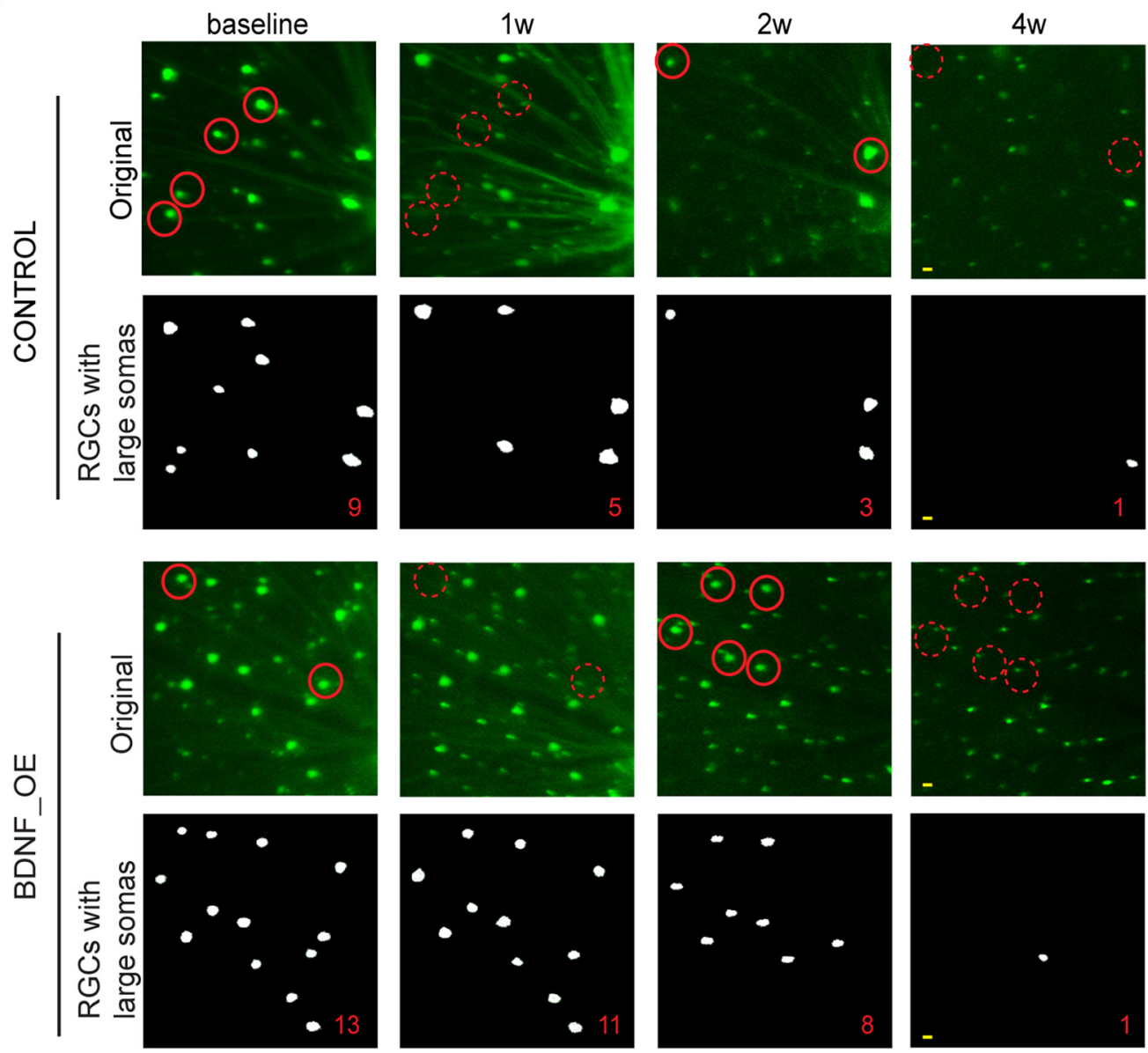

B

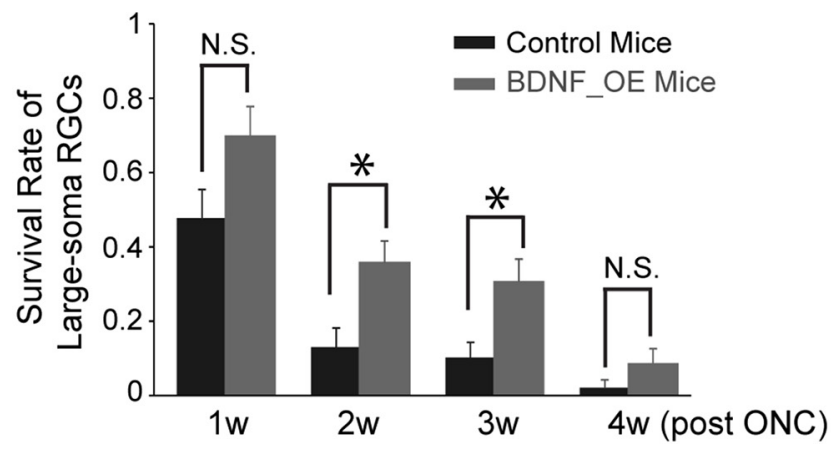

Figure 3. The loss of large-soma RGCs was delayed by BDNF overexpression. A, In vivo and Matlab-processed images show the progressive loss of large-soma RGCs after ONC. Number of surviving RGCs is shown at the bottom right of each image. Some examples of the large-soma cells are circled in solid red lines, and the same locations the next week are circled in dashed lines, demonstrating the disappearance of these large somas. Scale bar: $20 \mu \mathrm{m}$. B, More RGC somas survived in BDNF_OE than control mice. Control, $n=8$ mice; BDNF_OE, $n=11$ mice. N.S.: not significant; $* p<0.05$ by Student's $t$-test. Data are presented as mean \pm SEM.

\section{Overexpression of BDNF delayed the loss of large- soma RGCs after ONC}

In vivo imaging was performed before ONC (baseline) and then every week for 4 weeks after ONC (Fig. $3 A$ ). RGCs with large somas were tracked for mice with and without BDNF upregulation. In the control mice, only $48 \%$ $\pm 8 \%$ of RGCs survived for 1 week after ONC ( $n=8$ mice, 228 cells; Fig. 3B). The RGC loss continued, with just $16 \%$ $\pm 5 \%$ remaining at 2 weeks and $10 \% \pm 4 \%$ at 3 weeks
(Fig. 3B). After 4 weeks, most, if not all, RGCs had died $(2 \% \pm 2 \%$; Fig. $3 B)$. In contrast, in the BDNF_OE mice, RGC survival rates were $70 \% \pm 8 \%$ at 1 week $(n=11$, 416 cells), a change not statistically significant from control mice ( $p=0.06$ by Student's t-test; Fig. 3B). Many more cells survived at 2 weeks $(36 \% \pm 6 \%)$ and 3 weeks $(31 \% \pm 6 \%$; Fig. $3 B)$. However, by 4 weeks after ONC, BDNF_OE exhibited significant RGC loss $(9 \% \pm 4 \%)$ like the control group (Fig. 3B). Our data 
A
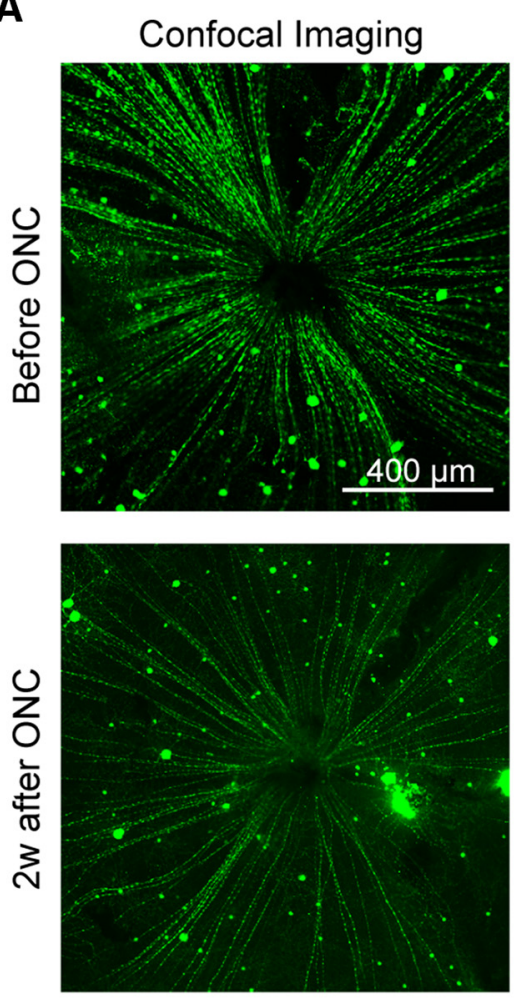

B

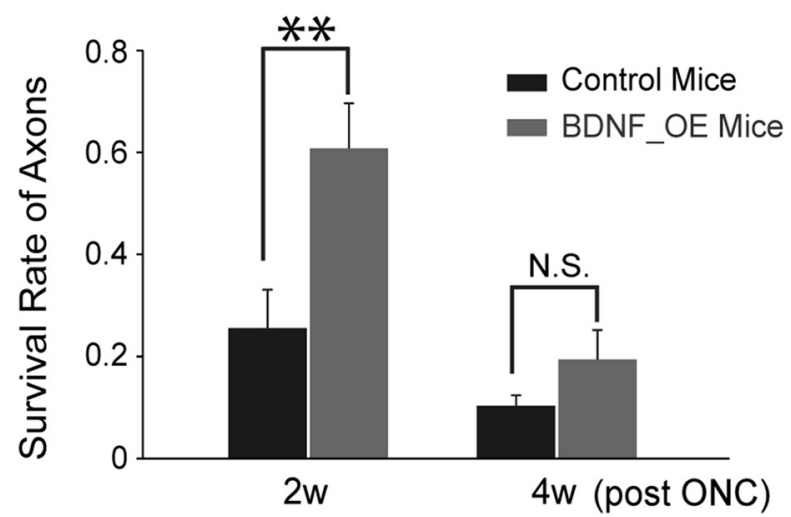

Axon counting by MATLAB
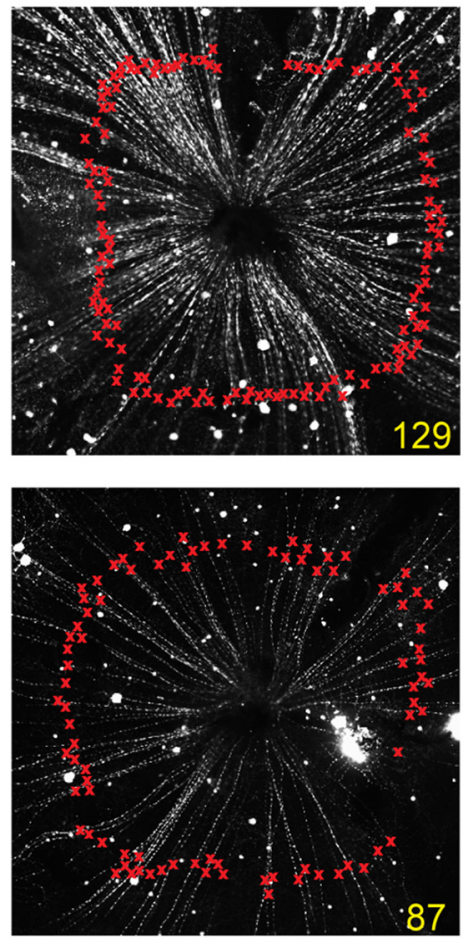

87

Figure 4. Axonal survival was also extended in BDNF_OE mice. $\boldsymbol{A}$, Confocal images of flat-mounted BDNF_OE retinas before and after ONC injury (left). Axons were immune-stained with anti-GFP antibody and counted with Matlab. Each red cross marks one axon by Matlab; the number was double-checked manually. B, RGC survival was significantly higher in BNDF_OE mice at 2 weeks after ONC. $n=4-5$ mice. N.S.: not significant; $* * p<0.01$ by two-way ANOVA, Sidak's multiple comparison posttest. Data are presented as mean \pm SEM.

thus suggest that overexpression of BDNF delays RGC loss after ONC.

We used the Kaplan-Meier estimator to model the survival probabilities of RGCs for control and BDNF_OE mice. The median survival time for controls in this study is $\sim 7 \mathrm{~d}$. For BDNF_OE mice, the median survival time of large-soma RGCs was $\sim 14 \mathrm{~d}$, significantly longer than for control mice ( $p<0.001$ by log-rank test). In other words, overexpression of BDNF prolongs survival for large-soma RGCs by $\sim 1$ week.

In addition, the median survival time for RGCs with large somas was 1 week less than we reported previously for median RGC survival in the Thy-1-YFP $(\mathrm{H})$ mouse line. Although the time difference of the two transgenic lines failed to reach statistical significance $(p=0.06$, two-way ANOVA), it indicates that large-soma RGCs may be among the most vulnerable to optic nerve trauma.

\section{Axon loss was also delayed in mice overexpressing BDNF after ONC injury}

We counted GFP-labeled axons from the entire retina with confocal imaging (Fig. 4A). Flat-mounted retinas were immunostained with anti-GFP antibody, and axon numbers were counted (Fig. 4A). Before ONC, the average axon number per retina was $167 \pm 8$ for control mice $(n=5$; Fig. 4A). Approximately $26 \% \pm 8 \%$ of axons survived 2 weeks after ONC ( $n=4$; Fig. $4 B$ ), a percentage consistent with our previous work $p=0.33$, Student's 
$t$-test; Puyang et al., 2016). At 4 weeks after injury, only $10 \% \pm 2 \%$ of axons survived in control mice $(n=4$; Fig. $4 B$ ), demonstrating again that RGC loss after optic nerve injury is progressive and rapid. We found that axon survival was enhanced in the BDNF_OE mice $(p<0.01$ by two-way ANOVA with Sidak's multiple comparison posttest; Fig. 4B). At 2 weeks after the injury, $61 \pm 9 \%$ of axons survived in BDNF_OE mice (102 \pm 15 axons, $n=4$ mice), much higher than for controls $(p<0.01$ by two-way ANOVA with Sidak's multiple comparison posttest; Fig. $4 B)$. At 4 weeks, axonal survival in BNDF_OE mice was $19 \% \pm 6 \%$ ( $n=4$ mice), twice the number for control mice, although the difference was not statistically significant $(p>0.05$ by two-way ANOVA; Fig. $4 B)$.

\section{Discussion}

Recent studies suggest that the structural and functional degeneration of RGCs is type dependent in mouse models of experimental glaucoma or optic neuropathy, yet there are interstudy inconsistencies concerning the vulnerability of different types of RGCs (Feng et al., 2013; Della Santina et al., 2013; Chen et al., 2015; Duan et al., 2015; El-Danaf and Huberman, 2015). Considering that the median survival time for RGCs in Thy-1-YFP-H mice was 2 weeks (Puyang et al., 2016), that the median survival time for large-soma RGCs reported here (Fig. 3C) was just 1 week after ONC indicates that this RGC subpopulation is unusually vulnerable to optic nerve injury. This result contrasts with that of Duan et al. (2015), which showed genetically labeled RGCs (mostly SMI-32 positive) surviving longer than average. Because the SMI-32positive large-soma RGCs account for only $11 \%$ of the total SMI-32 cells, our results suggest that SMI-32-positive cells may include different subgroups of RGCs, and each subgroup may respond to the insult differently.

There is also some disagreement among investigators about the vulnerability of ON RGCs cells to optic nerve injury or glaucomatous insult. We have found some SMI-32 ON cells to be more vulnerable to sustained IOP elevation (Feng et al., 2013), whereas another study reported that the ON layer of the IPL was unperturbed at an early stage of IOP elevation (El-Danaf and Huberman, 2015). Physiological studies of mouse RGCs have shown that ON cells have smaller receptive field centers after 5-7 weeks of IOP elevation (Chen et al., 2015) and lower spontaneous rates and light-evoked responses (Della Santina et al., 2013). In this study, we followed a small number of SMI-32-positive RGCs, most of which were ON cells $(71 \%$, Fig. $2 E)$. We found that these cells were unusually susceptible to ONC (Fig. 3). The weight of results therefore supports that these large-soma ON RGCs are more vulnerable to optic nerve insults than other RGC varieties. Further studies are needed to better classify individual RGC types to understand the mechanisms underlying the type-specific RGC loss in different animal models.

Furthermore, we employed in vivo imaging to follow the same RGCs over time, avoiding intersample variation after ONC (Leung et al., 2011; Feng and Liu, 2016; Puyang et al., 2016). Leung et al. (2011) applied a blue-light confocal scanning laser ophthalmoscope to track RGC survival in vivo using Thy-1-YFP-16Jrs transgenic mice. Puyang et al. (2016) used Thy-1-YFP-H mice and showed that the overall RGC survival rate decreased progressively after injury. We further confirmed that the overall survival of axons labeled by Thy-1-YFP-H and Thy-1-YFPCreER $^{\text {T2 }}$ exhibited no significant difference 2 weeks after ONC (Fig. 4B; current study and Puyang et al., 2016), suggesting that both transgenic lines provided consistent sampling of all RGCs and their axons. One encouraging future direction would be to combine in vivo imaging and transgenic mouse lines with specific RGC subtypes labeled to study RGC subtype loss at a fine granularity after disease insult.

We found that the survival of axons increased $\sim 1$.38fold by BDNF overexpression at 2 weeks after optic nerve injury (Fig. 4B). This increase is likely due to the increase of the survival rate observed in large-soma RGCs at the same stage (1.29-fold; Fig. 3B). Our studies suggest that BDNF encouraged the survival of large-soma RGCs after acute optic nerve injury. During normal development, type-specific regulation led by neurotrophin-3 and BDNF is important for the maturation of RGCs (Liu et al., 2007, 2009). In diseased conditions, the type-specific protection may explain the partial or incomplete neuroprotective effects observed in previous studies (Mey and Thanos, 1993; Chen and Weber, 2001; Weber et al., 2010; Feng et al., 2016). In addition, neuroprotective agents have targeted the multiple pathogenic mechanisms that result in axonal degeneration and RGC death, which include anti-apoptotic strategies, tumor necrosis factor- $\alpha$, antiexcitotoxic agents, and stem cells (Danesh-Meyer, 2011). The differential vulnerabilities of RGC subtypes are likely induced by diverse signaling pathways, and these different pathways may interact to activate apoptotic effects, which might explain that by the end of 4 weeks after ONC, the majority of RGCs were still lost in BDNF_OE retina.

Together, we find that (1) large-soma RGCs ( $11 \%$ of SMI-32-positive cells) are particularly susceptible to optic nerve injury; and (2) overexpression of BDNF prolongs the survival of RGCs, including large-soma RGCs.

\section{References}

Baden T, Berens P, Franke K, Román Rosón M, Bethge M, Euler T (2016) The functional diversity of retinal ganglion cells in the mouse. Nature 529:345-350. CrossRef Medline

Calkins DJ (2012) Critical pathogenic events underlying progression of neurodegeneration in glaucoma. Prog Retin Eye Res 31:702719. CrossRef Medline

Chader GJ (2012) Advances in glaucoma treatment and management: neurotrophic agents. Invest Ophthalmol Vis Sci 53:25012505. CrossRef Medline

Chen H, Weber AJ (2001) BDNF enhances retinal ganglion cell survival in cats with optic nerve damage. Invest Ophthalmol Vis Sci 42:966-974. Medline

Chen $\mathrm{H}$, Zhao Y, Liu M, Feng L, Puyang Z, Yi J, Liang P, Zhang HF, Cang J, Troy JB, Liu X (2015) Progressive degeneration of retinal and superior collicular functions in mice with sustained ocular hypertension. Invest Ophthalmol Vis Sci 56:1971-1984. CrossRef Medline

Danesh-Meyer HV (2011) Neuroprotection in glaucoma: recent and future directions. Curr Opin Ophthalmol 22:78-86. CrossRef Medline 
Della Santina L, Inman DM, Lupien CB, Horner PJ, Wong RO (2013) Differential progression of structural and functional alterations in distinct retinal ganglion cell types in a mouse model of glaucoma. J Neurosci 33:17444-17457. CrossRef

Di Polo A, Aigner LJ, Dunn RJ, Bray GM, Aguayo AJ (1998) Prolonged delivery of brain-derived neurotrophic factor by adenovirus-infected Müller cells temporarily rescues injured retinal ganglion cells. Proc Natl Acad Sci U S A 95:3978-3983. Medline

Duan X, Qiao M, Bei F, Kim IJ, He Z, Sanes JR (2015) Subtypespecific regeneration of retinal ganglion cells following axotomy: effects of osteopontin and mTOR signaling. Neuron 85:12441256. CrossRef Medline

El-Danaf RN, Huberman AD (2015) Characteristic patterns of dendritic remodeling in early-stage glaucoma: evidence from genetically identified retinal ganglion cell types. J Neurosci 35:23292343. CrossRef Medline

Feng L, Chen H, Yi J, Troy JB, Zhang HF, Liu X (2016) Long-term protection of retinal ganglion cells and visual function by brainderived neurotrophic factor in mice with ocular hypertension. Invest Ophthalmol Vis Sci 57:3793-3802. CrossRef Medline

Feng L, Liu X (2016) NLRP3 inflammasome in retinal ganglion cell loss in optic neuropathy. Neural Regen Res 11:1077-1078. CrossRef Medline

Feng L, Xie X, Joshi PS, Yang Z, Shibasaki K, Chow RL, Gan L (2006) Requirement for Bhlhb5 in the specification of amacrine and cone bipolar subtypes in mouse retina. Development 133:4815-4825. CrossRef Medline

Feng L, Zhao Y, Yoshida M, Chen H, Yang JF, Kim TS, Cang J, Troy JB, Liu X (2013) Sustained ocular hypertension induces dendritic degeneration of mouse retinal ganglion cells that depends on cell type and location. Invest Ophthalmol Vis Sci 54:1106-1117. CrossRef Medline

Harper MM, Grozdanic SD, Blits B, Kuehn MH, Zamzow D, Buss JE, Kardon RH, Sakaguchi DS (2011) Transplantation of BDNFsecreting mesenchymal stem cells provides neuroprotection in chronically hypertensive rat eyes. Invest Ophthalmol Vis Sci 52: 4506-4515. CrossRef Medline

Huang EJ, Reichardt LF (2003) Trk receptors: roles in neuronal signal transduction. Annu Rev Biochem 72:609-642. CrossRef Medline

Johnson EC, Guo Y, Cepurna WO, Morrison JC (2009) Neurotrophin roles in retinal ganglion cell survival: lessons from rat glaucoma models. Exp Eye Res 88:808-815. CrossRef Medline

Johnson TV, Bull ND, Martin KR (2011) Neurotrophic factor delivery as a protective treatment for glaucoma. Exp Eye Res 93:196-203. CrossRef Medline

Ko ML, Hu DN, Ritch R, Sharma SC, Chen CF (2001) Patterns of retinal ganglion cell survival after brain-derived neurotrophic factor administration in hypertensive eyes of rats. Neurosc Lett 305:139142. Medline

Leung CK, Weinreb RN, Li ZW, Liu S, Lindsey JD, Choi N, Liu L, Cheung CY, Ye C, Quu K, Chen LJ, Yung WH, Crowston JG, Pu M, So KF, Pang CP, Lam DS (2011) Long-term in vivo imaging and measurement of dendritic shrinkage of retinal ganglion cells. Invest Ophthalmol Vis Sci 52:1539-1547. CrossRef Medline
Liu X, Grishanin RN, Tolwani RJ, Rentería RC, Xu B, Reichardt LF, Copenhagen DR (2007) Brain-derived neurotrophic factor and TrkB modulate visual experience-dependent refinement of neuronal pathways in retina. J Neurosci 27:7256-7267. CrossRef Medline

Liu X, Robinson ML, Schreiber AM, Wu V, Lavail MM, Cang J, Copenhagen DR (2009) Regulation of neonatal development of retinal ganglion cell dendrites by neurotrophin-3 overexpression. $J$ Comp Neur 514:449-458. CrossRef Medline

Martin KR, Quigley HA, Zack DJ, Levkovitch-Verbin H, Kielczewski J, Valenta D, Baumrind L, Pease ME, Klein RL, Hauswirth WW (2003) Gene therapy with brain-derived neurotrophic factor as a protection: retinal ganglion cells in a rat glaucoma model. Invest Ophthalmol Vis Sci 44:4357-4365. CrossRef

Mey J, Thanos S (1993) Intravitreal injections of neurotrophic factors support the survival of axotomized retinal ganglion cells in adult rats in vivo. Brain Res 602:304-317. Medline

Morrison JC, Cepurna Ying Guo WO, Johnson EC (2011) Pathophysiology of human glaucomatous optic nerve damage: insights from rodent models of glaucoma. Exp Eye Res 93:156-164. CrossRef Medline

Nagahara AH, Tuszynski MH (2011) Potential therapeutic uses of BDNF in neurological and psychiatric disorders. Nat Rev Drug Discov 10:209-219. CrossRef Medline

Ou Y, Jo RE, Ullian EM, Wong RO, Della Santina L (2016) Selective vulnerability of specific retinal ganglion cell types and synapses after transient ocular hypertension. J Neurosci 36:9240-9252. CrossRef Medline

Pease ME, Zack DJ, Berlinicke C, Bloom K, Cone F, Wang Y, Klein RL, Hauswirth WW, Quigley HA (2009) Effect of CNTF on retinal ganglion cell survival in experimental glaucoma. Invest Ophthalmol Vis Sci 50:2194-2200. CrossRef Medline

Puyang Z, Chen H, Liu X (2015) Subtype-dependent morphological and functional degeneration of retinal ganglion cells in mouse models of experimental glaucoma. J Nat Sci 1:e103.

Puyang Z, Feng L, Chen H, Liang P, Troy JB, Liu X (2016) Retinal ganglion cell loss is delayed following optic nerve crush in NLRP3 knockout mice. Sci Rep 6:20998. CrossRef Medline

Sanes JR, Masland RH (2015) The types of retinal ganglion cells: current status and implications for neuronal classification. Annu Rev Neurosci 38:221-246. CrossRef Medline

Sun W, Li N, He S (2002) Large-scale morphological survey of mouse retinal ganglion cells. J Comp Neur 451:115-126. CrossRef Medline

Weber AJ, Viswanáthan S, Ramanathan C, Harman CD (2010) Combined application of BDNF to the eye and brain enhances ganglion cell survival and function in the cat after optic nerve injury. Invest Ophthalmol Vis Sci 51:327-334. CrossRef

Yoshida M, Feng L, Grimbert F, Rangarajan KV, Buggele W, Copenhagen DR, Cang J, Liu X (2011) Overexpression of neurotrophin-3 stimulates a second wave of dopaminergic amacrine cell genesis after birth in the mouse retina. J Neurosci 31:12663-12673. CrossRef Medline 